\title{
Geografías indígenas urbanas: el caso mapuche en La Pintana, Santiago de Chile ${ }^{1}$
}

\author{
Bastien Sepúlveda² y Paulina Zúñiga ${ }^{3}$
}

\begin{abstract}
RESUMEN
Para muchos pueblos indígenas, la ciudad se constituyó históricamente como un espacio de exclusión y dominación que los relegó en los confines de la idea misma de modernidad. Sin embargo, la construcción y reproducción de espacios colectivos permite hoy a estos pueblos resignificar su presencia y renegociar su posición en el mosaico urbano. Este artículo apunta a entender las recomposiciones territoriales que derivan de esta situación, basándose para ello en un trabajo de campo (entrevistas, observación participante y revisión de archivos) realizado entre los años 2013 y 2014 con asociaciones mapuches de la comuna de La Pintana, ubicada al sur del Gran Santiago. Junto con describir el proceso migratorio mapuche en Chile y las modalidades de constitución de una territorialidad mapuche urbana, se analiza el surgimiento de rukas en el transcurso de los últimos quince años en La Pintana. Se concluye de este análisis que la ciudad participa plenamente de las dinámicas territoriales que animan el mundo mapuche contemporáneo.
\end{abstract}

Palabras clave: Mapuche, Santiago de Chile, espacio urbano, territorialidad, geografía indígena.

\begin{abstract}
For many indigenous peoples, the city was historically constructed as a space of exclusion and domination that relegated them to the confines of the very idea of modernity. However, the current construction of collective spaces enables them to renegotiate their position within the urban fabric. This article aims at understanding the territorial reconfigurations that have arisen in this context, using data collected through a fieldwork (interviews, participatory observation and archival research) conducted between 2013 and 2014 with indigenous groups in La Pintana, located within the metropolitan area of Santiago. In addition to describing the processes of Mapuche migration in Chile and the modalities by which an urban territoriality is being formed, we also analyze the emergence of rukas over the last fifteen years in La Pintana. We conclude that urban areas clearly form a portion of the contemporary Mapuche territorial dynamics.
\end{abstract}

Key words: Mapuche, Santiago de Chile, urban space, territoriality, indigenous geography.

\footnotetext{
1 Este artículo resulta de una investigación financiada por el Centro Interdisciplinario de Estudios Interculturales e Indígenas (Centro FONDAP No 15110008) Los autores agradecen especialmente a las y los dirigentes mapuches entrevistados en el marco de esta investigación, por su tiempo y atención. De igual forma, se agradece a Marcela Palomino-Schalscha y a Nelson Martínez por sus valiosos comentarios a una versión previa de este trabajo. Artículo recibido
}

el 25 de abril de 2015, aceptado el 30 de junio de 2015 y corregido el 10 de septiembre de 2015.

2 Centro Interdisciplinario de Estudios Interculturales e Indígenas - ICIIS, Pontificia Universidad Católica de Chile (Chile).

E-mail: bastien_sepulveda@yahoo.fr

3 Instituto de Geografía, Pontificia Universidad Católica de Chile (Chile). E-mail: pbzuniga@uc.cl 
La presencia indígena urbana es un hecho cuya creciente importancia es conocida y documentada desde ya varias décadas, sabiendo que los así llamados "urbanos" pueden incluso llegar a representar, en algunos países, un sector mayoritario con respecto al total de población indígena. Es en particular el caso de Chile donde, según las cifras del censo del año 2002, 65\% de la población indígena residiría en el medio urbano (INE, 2005). En Chile como en otros países de América Latina, la ciudad se está imponiendo de hecho como un lugar central e ineludible en la geografía de los territorios indígenas. De tal modo que parece cada vez más difícil, por no decir riesgoso, abordar la cuestión territorial indígena sin considerar o contemplar de alguna manera su dimensión urbana. La comunidad científica en general, y los geógrafos en particular, no han sido indiferentes a esta realidad. Lo atestigua, entre otros, la publicación de varios libros colectivos (Howard \& Proulx, 2011; Newhouse \& Peters, 2003; Peters, 2012; Peters \& Andersen, 2013; Sejersen et al., 2008) y dossiers temáticos en revistas como Etudes/Inuit/Studies (Kishigami \& Lee, 2008), Acta Borealia (Dybbroe et al., 2010) o Environment and Planning A (Morgan \& Gulson, 2010), en que aparecen numerosas contribuciones firmadas por geógrafos.

En estos trabajos, las realidades indígenas urbanas están analizadas desde entradas temáticas diversas y en contextos regionales que abarcan desde el Ártico hasta Australia, pasando por Canadá, Estados Unidos, Nueva Zelanda e incluso por Japón. Pero lo que más Ilama la atención es el cambio experimentado en el enfoque con que se han abordado dichas realidades desde la geografía. Como lo han demostrado Anderson y Jacobs (1997) para el caso australiano, las transformaciones operadas en el campo de la geografía cultural en el transcurso de los 1980 y 1990 han facilitado una

"[...] transición de una geografía cultural cuyo propósito es la descripción de una entidad dada (los indígenas urbanos) a una geografía cultural que se interesa en los procesos complejos de definición, negociación y reivindicación de lo indígena (la indigeneidad y la ciudad)" (Anderson y Jacobs, 1997: 14).
Por su parte, Peters (2011) señala que, desde mediados de 1990, las investigaciones realizadas en Canadá en torno a la cuestión indígena urbana han permitido aseverar que no había incompatibilidad en ser a la vez indígena y urbano. Esta autora insiste, además, en que la continuidad existente entre el medio urbano donde han migrado muchos indígenas y el universo comunitario de origen invita a repensar tanto el sentido como la validez de la categoría "indígena urbano". Como lo afirma, "los que viven dentro y fuera de la ciudad son parte de una misma comunidad indígena, y las ciudades y las reservas se conectan en la medida que los individuos circulan entre estos espacios" (Peters, 2011: 92).

Por otro lado, estos trabajos han también evidenciado que la ciudad logra ser apropiada por los migrantes mediante la inscripción y reproducción de sus identidades -tanto individuales como colectivas- en determinados espacios. Se puede hablar al respecto de un proceso de territorialización, a través del cual un grupo se apropia simbólica y materialmente de un determinado espacio, inscribe su identidad, lo dota de significado y lo convierte finalmente en territorio, usando para ello de un variado repertorio de acciones y mecanismos. Son estos mecanismos de territorialización que nos interesa entender en este trabajo y que proponemos examinar a través del caso mapuche en Chile. Buscamos visualizar cómo el territorio mapuche, históricamente confinado al centro-sur del país, se ha ido extendiendo a la ciudad, y reconfigurando en ella, mediante procesos migratorios que lo transformaron tanto en su forma como en su naturaleza. Se demuestra, de este modo, que los territorios indígenas no son entidades inmutables y ahistóricas, sino que deben ser entendidos como objetos geográficos dinámicos y en constante redefinición.

En América Latina, si bien la situación de los pueblos indígenas en el medio urbano ha sido ampliamente discutida por las ciencias sociales, pocos son los trabajos que proponen un análisis desde una perspectiva geográfica. Podemos citar, sin embargo, la obra de Hiernaux-Nicolas (2000; 2005), enfocada en las migraciones indígenas y las modalidades de asentamiento y reproducción identitaria en el área metropolitana de México. Más recientemente, y para el caso que nos interesa en el 
marco de este artículo, se encuentra también el trabajo de Thiers (2012), quien ha analizado cómo, a través de la actualización y/o reinvención de distintas prácticas culturales en Santiago, la población mapuche lograba posicionarse en, y apropiarse del espacio urbano. Adicionalmente, valiosas reflexiones han sido desarrolladas desde la antropología sobre las recomposiciones identitarias mapuches en la ciudad, y en particular en Santiago (Aravena, 2002; Bello, 2002; Gissi, 2001; Imilan y Álvarez, 2008). A la par con retomar y proseguir estas reflexiones, el presente artículo propone contribuir a la formación de una geografía indígena urbana, que podríamos definir como el conjunto de formas y expresiones espaciales que plasman y (re)significan la presencia indígena y el despliegue de su identidad en el medio urbano.

Muchos de los 604.349 mapuches oficialmente censados el año 2002 (INE, 2005) residen hoy en los principales centros urbanos del país, a veces muy lejos del territorio histórico. El Gran Santiago, en particular, reúne cerca del tercio de la población mapuche total, conformándose así como un escenario propicio para entender y analizar la formación de geografías indígenas urbanas. Nos interesa, en este contexto, indagar en las recomposiciones identitarias y territoriales que sustentan estas geografías, buscando entender más específicamente la forma en que se inscribe y materializa la presencia mapuche en el Gran Santiago. Analizaremos para ello la construcción y reproducción de espacios identitarios mapuches en La Pintana, basándonos en un trabajo de campo realizado entre los años 2013 y 2014 con diversas asociaciones indígenas de esta comuna del sur oriente.

Tras contextualizar el proceso migratorio mapuche hacia la ciudad, explicando su evolución y sus dinámicas en el transcurso del siglo XX en Chile, nos interesaremos en los procesos a través de los cuales se ha ido -y se sigue- constituyendo una territorialidad mapuche urbana. Nos preguntaremos más explícitamente cómo se territorializan los migrantes mapuches en el medio urbano, considerando para ello, y de manera cruzada, la cuestión de la movilidad y del asentamiento, los procesos asociativos y la reconfiguración de su identidad cultural en un medio inicialmente ajeno. Finalmente, nos enfocaremos en la última sección del artículo en la experiencia específica del movimiento mapuche en la comuna de La Pintana. Presentaremos y analizaremos para ello una serie de datos recopilados a través de encuestas y entrevistas realizadas en terreno con actores claves. Al examinar las formas de inscripción y despliegue de la identidad mapuche en esta comuna, buscaremos destacar en qué medida y bajo qué modalidades la ciudad se halla incorporada a la estructura territorial indígena. Concluiremos así nuestro propósito con algunas reflexiones más genéricas en torno a los desafíos planteados por la consideración de la ciudad y de la urbanidad al momento de abordar la cuestión territorial indígena.

\section{El proceso migratorio mapuche en Chile}

Tras conquistar y anexar el territorio mapuche a su jurisdicción, a finales del siglo XIX, el Estado chileno sometió las familias mapuches a un proceso de radicación que se materializó en la creación y entrega de las Ilamadas reducciones (Bengoa, 1985). Las reducciones fueron mercedes de tierras, de superficie variable, entregadas en propiedad a jefes de familia en distintos sectores de las actuales regiones del Biobío, de La Araucanía y de Los Ríos. Este proceso se extendió entre 1884 y 1929 , período durante el cual se entregó un total de 3.078 títulos, cuya principal función consistió en ceñir los derechos territoriales indígenas y abrir formalmente paso a la colonización agrícola (González, 1986). Las reducciones sentaron así el primer antecedente legal de las comunidades mapuches, para las cuales conformaron la primera base territorial oficialmente reconocida ${ }^{4}$. Sin embargo, estos espacios fueron

\footnotetext{
4 Las tierras otorgadas en los títulos de merced rara vez cubrieron la totalidad de los terrenos efectivamente ocupados por las familias mapuches. Esta situación dio origen a numerosos y engorrosos procesos judiciales a través de los cuales las comunidades intentaron $-\mathrm{y}$, en muchos casos, siguen intentandorecuperar las tierras de las que consideraban haber sido usurpadas. Cabe precisar, por otra parte, que muchas familias simplemente quedaron al margen del proceso de radicación, siendo posteriormente
} 
rápidamente superados, debido a una presión demográfica cada vez más fuerte en su interior. Notemos, por ejemplo, que entre 1929 y 1963, el promedio de tierras disponibles en las reducciones pasó de 6,1 ha a 1,8 ha por persona, lo cual llevó un número importante de individuos a migrar en busca de mejores alternativas fuera del ámbito reduccional (Almonacid, 2008).

La ciudad se presentó, en este contexto, como un destino privilegiado para muchos migrantes que se orientaron tanto hacia los centros urbanos regionales, cercanos a las reducciones, como hacia las principales urbes del país. Es de notar que, bajo el impulso del Plan General de Fomento Industrial, y en particular con la creación de la Corporación de Fomento de la Producción (CORFO) en 1939, las grandes urbes chilenas se convirtieron en polos de atracción para muchos migrantes provenientes de distintos sectores rurales del país, en busca de trabajo y mejores condiciones de vida. El punto es que, al generar nuevas fuentes de empleo, el proceso de industrialización impulsado acarreó un importante fenómeno de expansión y crecimiento urbano. La instalación e inauguración en 1950 de la planta siderúrgica de Huachipato en la conurbación Concepción-Talcahuano -el área metropolitana más grande del país después de Santiago- es un ejemplo paroxístico de aquello, siendo un factor determinante en los importantes procesos migratorios que se generaron hacia la zona a partir de la década de 1950 (Aliste, 2010).

En lo que respecta a los mapuches más específicamente, se estima que, ya en la década de 1960 , entre $15 \%$ a $25 \%$ de esta población había migrado fuera de su comunidad de origen. En el transcurso de los años 1970, el antropólogo Stuchlik (1976) consideraba que casi la mitad de la población mapuche masculina en edad adulta ya había migrado. La posterior sistematización del proceso de división de la propiedad indígena, impulsada por el régimen militar a partir de 1979 (Rupailaf, 2002), contribuyó indudablemente a acentuar el fenómeno migratorio.

reconocidas sus posesiones territoriales -parcialmente, de nuevo-, mediante diversos mecanismos.
Pues, el hecho de establecer y otorgar parcelas individuales en propiedad a cada jefe de familia en las antiguas reducciones inhibió, por una parte, la capacidad de redistribución de los lonkos ${ }^{5}$. Por otra parte, dicho proceso no consideró los derechos de quienes, por distintos motivos, no se encontraban al momento de las mensuras y posterior entrega de los títulos de dominio, viéndose así privados de un acceso a la propiedad.

Pese a la evidencia del fenómeno, durante muchos años, los censos de población siguieron encapsulando a la población mapuche en una exclusiva y atemporal identidad campesina. Al prevalecer la reducción como único y restringido marco de referencia para censar la población mapuche, no se consideró la condición étnica de los migrantes establecidos en los distintos centros urbanos del país. Se realizó sin embargo un primer recuento oficial en 1952, aunque ciñéndose al caso de Santiago, donde se registró un total de 875 mapuches. Según Munizaga (1971), se habría subestimado una realidad mucho más significativa, considerando que tan solo en los registros electorales de la provincia de Santiago se contaba ya, en ese entonces, cerca de 10.000 inscritos portando por lo menos un apellido de origen mapuche. Otra estimación, arrojada por Saavedra (2002), señala que, para el año 1966, cerca de 40.000 mapuches ya se habían establecido en las distintas ciudades del país. Por su parte, Stuchlik (1976) considera que esta cifra se habría acercado más probablemente a las 100.000 personas.

Las cosas cambiaron recién a partir del año 1992, cuando se incorporó oficialmente, por primera vez, la pertenencia étnica como variable dentro del Censo de Población. Los resultados del Censo de 1992 dejaron entonces en evidencia una realidad que contrastaba fuertemente con la representación que la sociedad chilena se había forjado de los pueblos indígenas. Contrarrestando el imaginario de un mapuche rural, ligado a la vida en reducción y una cultura tradicional casi inmutable, el Censo de 1992 develó una insospechada tasa de urbanización -cerca del

\footnotetext{
5 La palabra lonko significa "cabeza" en mapudungun y se usa para designar al jefe o autoridad tradicional del lof o comunidad (ver Nota $\mathrm{N}^{\circ} 8$ ).
} 
Cuadro $\mathrm{N}^{\circ} 1$

Datos demográficos de la población mapuche en los censos de 1992 y 2002

\begin{tabular}{|c|c|c|c|c|c|}
\hline \multirow{2}{*}{ Región } & \multicolumn{2}{|c|}{ Población mapuche 1992} & \multicolumn{2}{|c|}{ Población mapuche 2002} & \multirow{2}{*}{$\begin{array}{c}\text { Variación } \\
\text { 2002-1992 (\%) }\end{array}$} \\
\hline & Individuos & $\%$ & Individuos & $\%$ & \\
\hline Tarapacá & 9.557 & 1,02 & 5.443 & 0,90 & $-43,05$ \\
\hline Antofagasta & 12.053 & 1,29 & 4.382 & 0,73 & $-63,64$ \\
\hline Atacama & 6.747 & 0,72 & 2.223 & 0,37 & $-67,05$ \\
\hline Coquimbo & 18.010 & 1,94 & 3.549 & 0,59 & $-80,29$ \\
\hline Valparaíso & 58.945 & 6,35 & 14.748 & 2,44 & $-74,98$ \\
\hline Metropolitana & 409.079 & 44,07 & 182.918 & 30,27 & $-55,29$ \\
\hline O'Higgins & 35.579 & 3,83 & 10.079 & 1,67 & $-71,67$ \\
\hline Maule & 32.444 & 3,49 & 8.134 & 1,35 & $-74,93$ \\
\hline Biobío & 125.180 & 13,48 & 52.918 & 8,76 & $-57,73$ \\
\hline Araucanía & 143.769 & 15,49 & 202.970 & 33,58 & 41,18 \\
\hline Los Lagos & 68.727 & 7,40 & 100.664 & 16,66 & 46,47 \\
\hline Aysén & 3.256 & 0,35 & 7.604 & 1,26 & 133,54 \\
\hline Magallanes & 4.714 & 0,50 & 8.717 & 1,44 & 84,92 \\
\hline Total & 928.060 & 100 & 604.349 & 100 & $-34,88$ \\
\hline
\end{tabular}

Fuente: Elaboración propia, en base a datos disponibles en http://www.ine.cl

$80 \%-$, resultante de un importante y antiguo flujo migratorio desde las comunidades del sur hacia los principales centros urbanos del país. Al dejar que los individuos, independientemente de su lugar de residencia, se identificaran libremente con uno de los tres grupos indígenas entonces formalmente reconocidos por el Estado chileno -i.e. mapuche, aimara y rapa nui-, el Censo de 1992 permitió desarraigar lo mapuche del ámbito reduccional (Aravena, 2014) ${ }^{6}$.

De hecho, más que la importancia tanto absoluta como relativa de la población mapuche -900.000 individuos, es decir cerca del $10 \%$ de la población chilena-, lo que llamó la atención fue su distribución geográfica. Esta ya no coincidía exclusivamente con las regiones tradicionales de asentamiento -entre las regiones del Biobío y de Los Lagos-, que solo albergaban el $36 \%$ de una población

\footnotetext{
6 La pregunta insertada en la encuesta censal fue: "Si usted es chileno, ¿se considera perteneciente a alguna de las siguientes culturas?: a) mapuche, b) aimara, c) rapa nui, y d) ninguna de las anteriores".
}

cuyo mayor contingente se concentraba en la Región Metropolitana $-44 \%$ del total (Cuadro $\mathrm{N}^{0} 1$ )-. Más sorprendente aún, fue el darse cuenta que, en Santiago, la proporción de urbanos -es decir los mapuches nacidos y criados en Santiago- era mayor a la de los migrantes, significando por consiguiente que la tasa de urbanización registrada era fuertemente ponderada por el crecimiento endógeno de una población instalada ya en Santiago desde por lo menos una generación (Valdés, 1996).

El Censo de 2002, si bien confirmó esta tendencia, registró una baja del orden de $35 \%$ con respecto al total de población mapuche censada en 1992. Es probable que esta situación haya resultado de la modificación realizada en la pregunta destinada a censar la identidad étnica de los individuos, formulada esta vez en términos de pertenencia y no de autoadscripción 7 . Pero más allá de esta baja,

\footnotetext{
7 Se preguntó, precisamente: “¿Pertenece usted a alguno de los siguientes pueblos originarios o indí-
} 
Figura $\mathrm{N}^{\circ} 1$

Distribución de la población mapuche en Chile en 2002

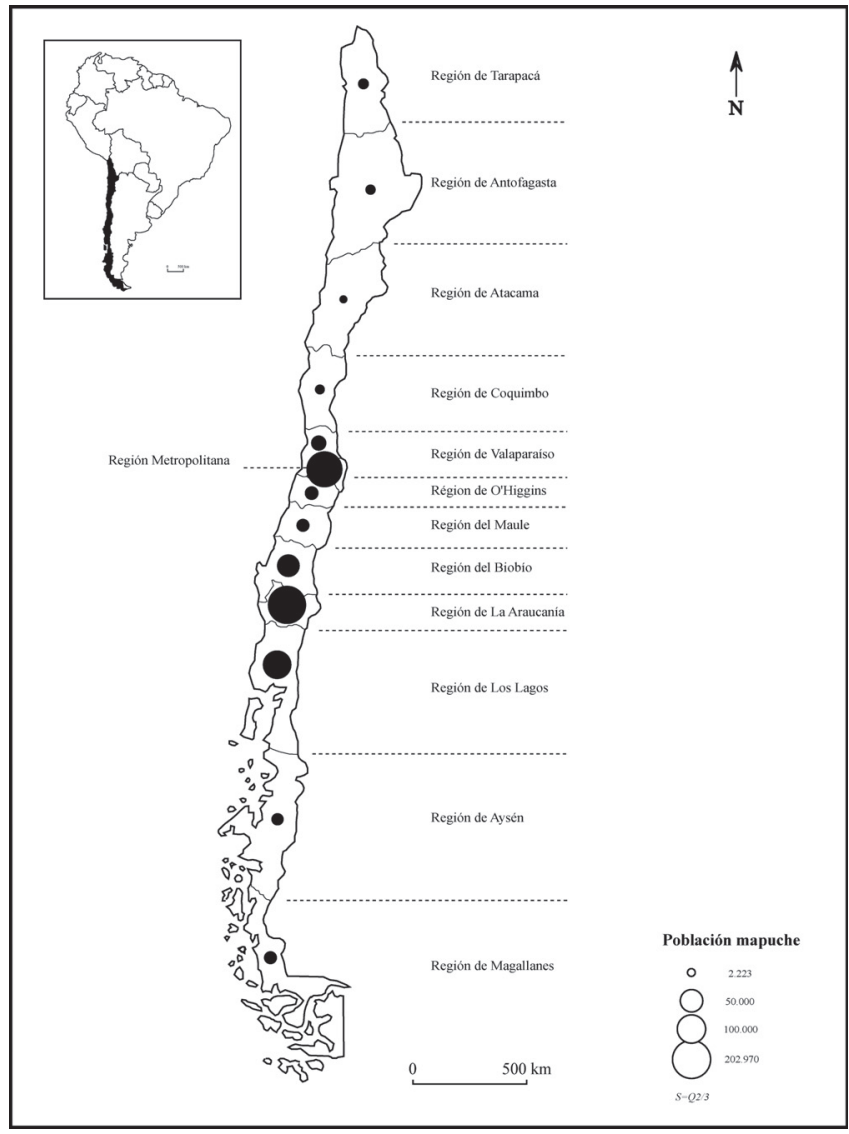

Fuente: Elaboración propia.

es la redistribución de la población mapuche en su territorio histórico que merece ser destacada (Figura $N^{\circ} 1$ ). Cuando, en 1992, se anunciaba que las regiones de poblamiento histórico agrupaban tan solo el $36 \%$ de los mapuches, la cifra publicada en 2002 ascendió al 59\%. Por su parte, la Región Metropolitana no reunía más del $30 \%$. No obstante, la tasa de urbanización seguía siendo relativamente alta, indicando que un $65 \%$ de la población mapuche residía en el medio urbano.

genas? 1) alacalufe (kawashkar), 2) atacameño, 3) aimara, 4) colla, 5) mapuche, 6) quechua, 7) rapa nui, 8) yámana (yagán), o 9) ninguno de los anteriores".

\section{La constitución de una territorialidad mapuche urbana}

En esta segunda sección, buscaremos identificar los elementos en torno a los cuales se logra articular una geografía indígena urbana, dando cuenta, para ello, de las formas de inscripción de la población mapuche en el mosaico urbano. Dicho de otro modo, intentaremos develar cómo y en qué medida se vuelven a dibujar, en la urbe, los contornos del territorio mapuche. Así, mostraremos, en primer lugar, cómo el barrio se fue constituyendo en un espacio de referencia y (re) producción de la identidad mapuche en el medio urbano. Insistiremos en esta ocasión en el rol de los lazos de parentesco como base fundamental y mecanismo de reproduc- 
ción de una sociabilidad mapuche urbana. A la luz de estos antecedentes, analizaremos luego la configuración de la esfera asociativa mapuche urbana formada en el surco de la Ley Indígena de 1993 que institucionalizó la figura de Asociación Indígena. Al destacar el peso del parentesco en la formación de estas asociaciones y su consecuente arraigo en determinados barrios, mostraremos finalmente cómo el municipio se ha visto convertido en el espacio de referencia a la vez que el marco de acción del tejido asociativo mapuche urbano.

\section{El barrio como espacio de referencia}

A su llegada a la ciudad, muchos migrantes mapuches se insertaron $-y$ se siguen insertando-a través del trabajo "puertas adentro", una modalidad de contratación que contempla el alojamiento como parte de la retribución por las labores realizadas. Mientras muchas mujeres se emplearon en el trabajo doméstico (Millaleo, 2011), los hombres encontraron "refugio" en las panaderías de los centros urbanos (Imilan y Álvarez, $2008)^{8}$. Esta modalidad de inserción sigue prevaleciendo en la actualidad, pero muchos ya consiguieron una vivienda propia, trans-

\footnotetext{
8 En esta etapa de inserción a la vida urbana, la sociabilidad de los migrantes se suele articular en torno al recorrido de algunos lugares populares y asiduamente visitados los días de descanso del trabajo puertas adentro. En Santiago, el más famoso de estos lugares fue, durante muchas décadas, el Parque Quinta Normal que Lorenzo Aillapan menciona en varias ocasiones en su relato autobiográfico, y califica incluso como el "lugar privilegiado de reunión de los mapuches" (Aillapan en Munizaga, 1971: 48). Ese era el lugar donde uno podía encontrarse con sus parientes cercanos o lejanos, pero también con otros migrantes, y en algunos casos, incluso, con su futura/o esposa/o. Esta búsqueda y producción de espacios de sociabilidad se repite también en numerosos otros contextos de similares características. En México, por ejemplo, donde el trabajo doméstico también ha sido y sigue siendo una forma privilegiada de inserción a la vida urbana para una mayoría de mujeres indígenas, la Alameda Mariano Escobedo en Monterrey constituye, al igual que el Parque Quinta Normal en Santiago, un espacio informal fundamental de sociabilidad para los migrantes indígenas (Díaz, 2008). Es de hecho una constante entre las comunidades de migrantes, y en particular entre los migrantes indígenas en América Latina que, al Ilegar a la ciudad, reinventen, reproduzcan y fijen su identidad colectiva en los intersticios del mosaico urbano.
}

formándose en un vínculo fundamental para la llegada de otros parientes. Como lo señala Aravena (2002: 367), existiría lo que ella llama una tradición migratoria, "que consiste en el hecho que, una vez alcanzada una cierta estabilidad laboral cada migrante constituye una suerte de puente para que otros integrantes de su familia se les una". Resultó de esta lógica un proceso de aglutinamiento de la población mapuche en determinados sectores, generalmente en las comunas periféricas y socialmente más vulnerables, que "nos lleva a ver los barrios periféricos de Santiago no solamente como lugares de concentración y reproducción de la pobreza urbana sino también como espacios de segregación socioétnica" (Aravena, 2002: 370).

En algunas de estas comunas, como Cerro Navia o La Pintana -que estudiaremos más en detalle a continuación-, la población mapuche representaría, según los datos del Censo 2002, más del 6\% de la población comunal total (Figura $\mathrm{N}^{\circ} 2$ ). A la escala del barrio, las cifras son aún más significativas. Por ejemplo, un estudio realizado por Gissi (2001) en la comuna de Cerro Navia demostró que cerca del $30 \%$ de los habitantes de la población Sara Gajardo eran mapuches. Según Valdés (1996), esta situación caracterizaría cerca del $58 \%$ de la población mapuche censada en las nueve comunas con mayor concentración de población indígena del Gran Santiago. El mismo autor destaca incluso que, en algunas manzanas, la concentración de población mapuche llega a superar un 50\% del vecindario, y puede alcanzar excepcionalmente hasta un $90 \%$. Es frecuente, en estos casos, que muchos de estos vecinos sean parientes -de hasta tres generaciones- y que los mayores hayan migrado desde una misma comunidad o sector de origen. "Es fácil deducir -precisa el autor- que aquellas manzanas tienen una forma de interrelación y de producción social similar al comportamiento del Lof" (Valdés, 1996: 50) $)^{9}$.

El rol del parentesco en los patrones de distribución de la población mapuche daría

\footnotetext{
9 El lof corresponde al primer nivel de organización sociopolítica mapuche y se sustenta en los lazos de parentesco que vinculan a sus integrantes, los cuales conforman una familia extensa.
} 
Figura $\mathrm{N}^{\circ} 2$

Densidad de población mapuche en las comunas del Gran Santiago

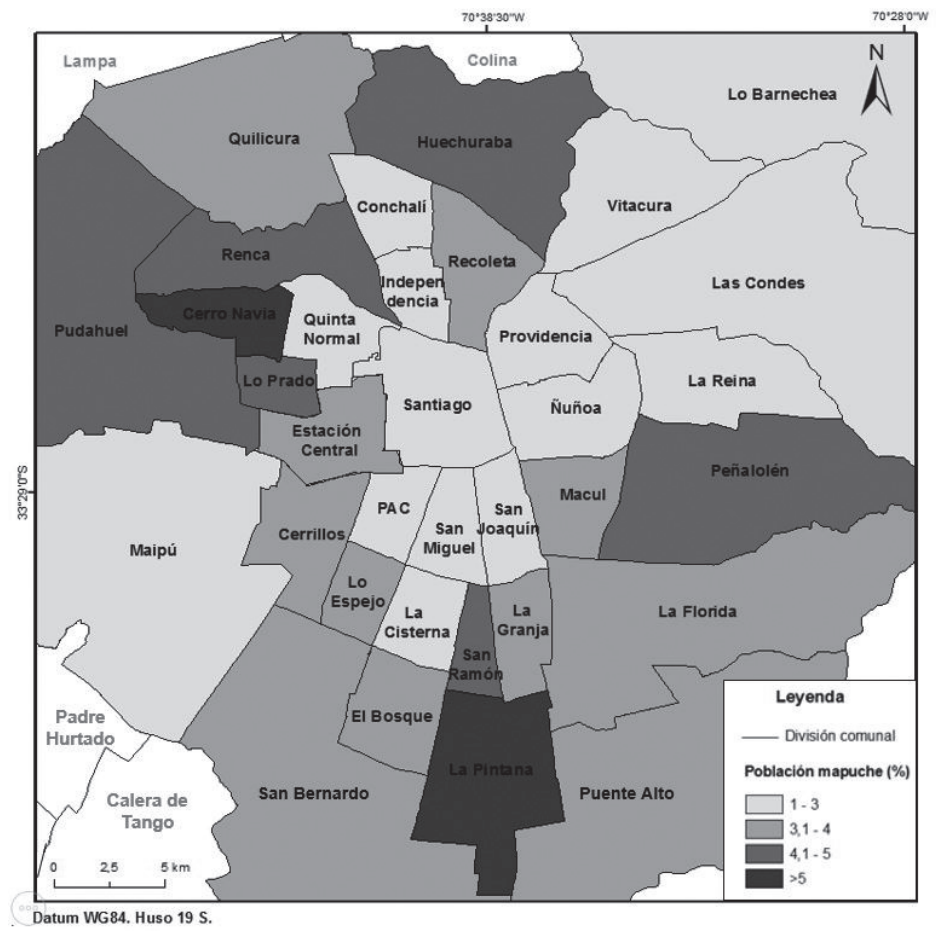

Fuente: Elaboración propia.

lugar, en este sentido, a lo que Gissi (2001) define como un proceso de producción incesante de diferenciación y autosegregación, haciendo del barrio un nuevo grupo socioterritorial de referencia. Así también, la activación de estos lazos constituye una plataforma esencial para la inserción laboral del grupo familiar en el medio urbano, considerando que "una cantidad importante de familias mapuches [ejercen] una actividad económico-productiva de carácter asociativo, donde habitualmente varios miembros de la familia [comparten] una misma actividad" (Aravena, 2002: 374). Junto con permitir la cohesión del grupo familiar, estas lógicas económicas acompañan, consolidan y participan plenamente de un proceso de territorialización que, como ya lo señaló Valdés (1996), se materializa en la reestructuración del lof en el espacio urbano.

Al asentarse en determinados barrios de la periferia urbana, muchos mapuches empezaron también a participar en organizaciones comunitarias como juntas de vecinos, centros de madres o centros culturales y artísticos que, hasta el día de hoy, constituyen plataformas formales de organización dependientes de los municipios ${ }^{10}$. Si bien muchos mapuches se sumaron en las organizaciones comunitarias como meros pobladores, estas pudieron constituir, en ocasiones, el espacio de una "etnicidad clandestina" que, hasta comienzo de los 1990, no tuvo ningún canal formal de expresión ${ }^{11}$. Pues, tanto las políti-

\footnotetext{
10 Las organizaciones comunitarias fueron formalmente establecidas en 1968 por la Ley $N^{\circ} 16.880$ sobre Juntas de Vecinos y demás organizaciones comunitarias, la cual fue refundada en 1989 por la Ley $\mathrm{N}^{\circ}$ 18.893 sobre organizaciones comunitarias territoriales y funcionales.

${ }^{11}$ En los sectores de alta concentración mapuche, algunas Juntas de Vecinos en particular pudieron asemejarse a verdaderas organizaciones étnicas, componiéndose sus directivas tal un consejo comunitario actuando en representación de las distintas familias en presencia.
} 
cas indigenistas de la Unidad Popular (19701973) como del régimen militar (1973-1990) se enfocaron exclusivamente en la cuestión de las tierras mapuches: el primero en el marco de la reforma agraria, el segundo a través de un proceso muchas veces calificado de contrarreforma agraria y liquidación de la propiedad colectiva indígena. La cuestión indígena urbana simplemente no tenía cabida en las discusiones de la época. Fue recién con el advenimiento de la democracia y la promulgación de una nueva legislación indígena que las cosas empezaron a cambiar.

\section{La ley indígena de 1993 y la figura de Asociación Indígena}

1970 y 1980 fueron marcados por las reinvidicaciones de muchos pueblos indígenas que, en distintas regiones de América Latina, a través de sus organizaciones y en forma creciente y cada vez más coordinada, expresaron una serie de demandas, relativas a las tierras y al territorio, pero también a la participación política en distintos ámbitos. En Chile, con el fin de atender estas demandas, el primer gobierno del período postdictadura conformó, en 1990, una Comisión Especial de Pueblos Indígenas (CEPI) que trabajó en la preparación de una nueva legislación indígena. Así, el 28 de septiembre de 1993, se promulgó la Ley $N^{\circ} 19.253$ que "establece normas sobre protección, fomento y desarroIlo de los indígenas, y crea la Corporación Nacional de Desarrollo Indígena (CONADI)".

Son muchos los aspectos de esta ley que merecerían ser destacados, pero nos interesaremos más específicamente, para el propósito de este trabajo, en el Título VIII en que se incluyó un párrafo sobre "Disposiciones Particulares para los Indígenas Urbanos y Migrantes". Los tres artículos que componen este párrafo atienden, respectivamente, la definición de las categorías de indígena urbano y migrante (Artículo $N^{\circ}$ 75), la conformación de asociaciones indígenas urbanas (Artículo $N^{\circ} 76$ ), y el rol de la CONADI en promover el bienestar de los indígenas en el medio urbano (Artículo $\left.N^{\circ} 77\right)^{12}$. Esta situación, inédi-

\footnotetext{
12 El texto completo es accesible en: http://www.conadi.gob.cl/documentos/Leylndigena2010t.pdf
}

ta en el contexto de las políticas indigenistas en Chile, resultó, por cierto, de la cada vez más masiva y evidente presencia indígena en los centros urbanos del país. Pero también, en cierta medida, de la afirmación, en el escenario de la transición democrática, de un poderoso movimiento mapuche intrínsecamente articulado con el mundo urbano.

Sin embargo, es a los efectos que tuvo este histórico -aunque limitado- reconocimiento de la categoría de indígena urbano que debe prestarse mayor atención. Pues, al establecer la existencia jurídica del indígena urbano, es decir al transformarlo en un sujeto de derecho y favorecer su participación a través de la figura de Asociación Indígena (A.I.), se fue conformando una clientela indígena urbana cada vez más numerosa y demandante. Según lo establece la ley indígena de 1993, en su Artículo N 36, una Asociación Indígena se define como "la agrupación voluntaria y funcional integrada por, a lo menos, veinticinco indígenas que se constituyen en función de algún interés y objetivo común de acuerdo a las disposiciones de este párrafo"; precisando además, en el Artículo $N^{\circ} 37$, que el objetivo de una A.I. "podrá ser, entre otros, el desarrollo de las siguientes actividades: a) educacionales y culturales; b) profesionales comunes a sus miembros, y c) económicas que beneficien a sus integrantes tales como agricultores, ganaderos, artesanos y pescadores".

Como se puede apreciar, la figura de A.I. no fue pensada específicamente para el mundo indígena urbano. Pero lo cierto es que, en la práctica, los mapuches urbanos la adoptaron y supieron utilizarla en su beneficio, en particular para acceder a distintas fuentes de financiamiento de proyectos productivos, culturales, educativos, etc., a los cuales no podían optar de otra forma. De hecho, varias A.I. surgieron a partir de agrupaciones de distintas índoles -socioculturales, sindicales, deportivas, religiosas, etc.-, eventualmente formalizadas como organizaciones comunitarias, que pese a no haber sido definidas en clave étnica, constituyeron espacios de sociabilidad fundamentales en que muchos mapuches, además de encontrarse, pudieron interactuar con diversos actores y hacerse partícipes de procesos amplios a nivel del 
vecindario ${ }^{13}$. En el caso de las A.l. más recientes, en cambio, notamos que fueron emergiendo en el surco de las primeras, incentivadas por las nuevas disposiciones de la legislación indigenista.

Este proceso fue particularmente fuerte en la Región Metropolitana donde, ya al año 2004, se registraba la existencia de más de un centenar de A.I. (Millaleo, 2006). Más allá de este aparente dinamismo, la gran cantidad de A.I. registradas no reunía sin embargo más de 4.858 adherentes, considerando además la posibilidad de inscripciones simultáneas de ciertos individuos en dos o más entidades. Descontando las inscripciones múltiples, la cifra de adherentes participando en las A.I. registradas el año 2004 en la Región Metropolitana se reducía entonces a 4.373 , es decir apenas 2,5\% de la población mapuche a nivel regional (Millaleo, 2006). Hoy, el número de asociaciones habría ascendido a cerca de doscientas (Carmona, 2014).

\section{Un movimiento mapuche estructurado en torno al municipio}

Trabajos previos realizados en el área metropolitana de Concepción han permitido demostrar el peso del parentesco en la conformación y configuración de las A.I. que tienden, en consecuencia, a arraigarse en determinados barrios o sectores de determinadas comunas (Sepúlveda, 2011). La fuerza de estos vínculos ha hecho de la comuna el marco de referencia del tejido asociativo mapuche urbano que, pese a una tasa relativamente baja de participación, ha tenido una presencia notable y cada vez más significativa, particularmente en el ámbito municipal. El municipio se ha ido convirtiendo efectivamente en un escenario propicio para que las A.I. cobraran existencia, plasmaran su protagonismo y se hicieran visibles. Es ahí precisamente donde los dirigentes mapuches urbanos plantean sus movilizaciones, donde

\footnotetext{
13 Para profundizar en esta materia, invitamos a consultar las entrevistas realizadas por Aravena a distintos dirigentes mapuches de Santiago y publicadas en el libro "Mapuches en Santiago. Memorias de inmigrantes y residentes. Relatos para una antropología implicada sobre indígenas urbanos" (Aravena, 2007).
}

proyectan sus acciones y buscan el reconocimiento de un espacio propio.

$\mathrm{Y}$ es, en primer lugar, el reconocimiento de un espacio institucional, de un lugar formal en la administración municipal, lo que motiva la acción colectiva indígena en el medio urbano. Esta búsqueda se ha plasmado, en muchas comunas de la Región Metropolitana, a través de una petición por establecer Oficinas de Asuntos Indígenas (OAI) con el fin de "[ejecutar] las políticas públicas, [orientar] a la población respecto a la institucionalidad en materia indígena, [apoyar] la solicitud de certificados de calidad indígena y el proceso de postulación a la Beca Indígena que entrega la JUNAEB" (Carmona, 2014: 9798). Como lo veremos más adelante, el municipio de La Pintana fue el primero, en 1996, en implementar su OAI, pero rápidamente lo siguieron otros municipios de la región ${ }^{14}$, donde se diseñaron:

“[...] programas de promoción y atención a la población mapuche, entre los que se encuentran jardines de infantes "étnicos", bibliotecas y centros culturales. Dentro de estos programas se destaca un creciente interés por la medicina tradicional administrada por los machi o chamanes, quienes ocupan un lugar central dentro de los procesos de reapropiación y resignificación de la cultura mapuche en contextos urbanos" (Bello, 2002: 42).

Para impulsar estas políticas y asegurar incluso su conducción, se ha vuelto común ver dirigentes mapuches presentar su candidatura en elecciones locales, y en particular en las elecciones municipales donde codician tanto los cargos de concejal como de alcalde ${ }^{15}$.

\footnotetext{
${ }^{14} \mathrm{Al}$ día de hoy, se ha establecido un total de 27 OAI en toda la Región Metropolitana (Carmona, 2014).

15 Esta dinámica participa de un proceso mayor que ha marcado la evolución histórica del movimiento mapuche. Los líderes de las primeras organizaciones del período postpacificación ya habían visualizado su participación en el sistema político formal, a través de los comicios, como una posibilidad de inferir en la toma de decisiones que podrían afectar a su destino como pueblo. De este modo, varios han sido los dirigentes de alguna organización mapuche que lograron ser elegidos como diputado en el transcurso del siglo XX. Así también, con la redemocratización del país, la elección de los alcaldes y,
} 
Es frecuente que, en estas circunstancias, los candidatos mapuches hagan de su condición étnica un elemento central de su campaña, afirmando de esta manera representar los intereses de la comunidad mapuche urbana ante las instancias municipales. Fue por ejemplo el caso de Marcela Lincovil, quien se presentó sucesivamente como concejala independiente para la comuna de La Florida en las elecciones municipales de 2012, y como consejera regional independiente para la $5^{\mathrm{a}}$ Circunscripción de Santiago (que incluye las comunas de La Florida, Peñalolén, Macul, La Granja y San Joaquín) en las elecciones de consejeros regionales de 2013. En una entrevista realizada en octubre de 2012 al diario La Nación, la entonces candidata independiente al cargo de concejala para la comuna de La Florida respondía de la siguiente manera a una pregunta sobre lo que su elección podría aportar a la realidad del electorado indígena de la comuna:

"Se puede instalar una política de desarrollo indígena o más concretamente una Oficina de Asuntos Indígenas que no dependa de otros organismos. Los que hay actualmente están bajo administración de la DIDECO o un departamento mayor, pero no un sector propio. Como concejala podemos apoyar demandas que se presenten a la autoridad y hacer lobby para que se realicen trabajos de este tipo en la comuna pero con recursos propios y mayor independencia, porque las alternativas que existen actualmente no nos han servido como grupo indígena" 16 .

Aún más interesante resulta su reacción a la siguiente pregunta sobre las necesidades concretas que ella identifica para la población indígena de la comuna, a lo cual responde: "Los problemas de las organizaciones sociales es que no tienen espacios físicos para reunirse. No hay una sede para juntarse

más recientemente, de los concejales, esta lógica se ha desplazado a la escala del municipio donde los candidatos mapuches disputan el acceso al sillón municipal.

${ }^{16}$ La entrevista completa está disponible en: http:// www.lanacion.cl/candidata-a-concejal-mapuche-en-nuestra-cultura-no-existen-divisiones/ noticias/2012-10-26/164936.html (consultado el 28/01/15). o para desarrollar actividades". La respuesta formulada por la candidata Lincovil es clave, en tanto ilustra la búsqueda del movimiento mapuche urbano por inscribirse en el mosaico urbano mediante la apropiación de una porción del espacio comunal, el reconocimiento de un espacio propio donde realizar las reuniones y demás actividades inherentes a la vida asociativa. En la siguiente sección, enfocamos nuestra atención al surgimiento de estos espacios en la comuna de La Pintana y a sus implicancias en términos territoriales. Cabe precisar que La Pintana se configura como un interesante caso de estudio, toda vez que, como ya lo hemos señalado más arriba, además de contar con una importante población mapuche, es la comuna donde se instaló la primera OAI de la región, lo cual como veremos se vincula a la gestación de un importante movimiento asociativo desde mediados de 1990.

\section{La experiencia mapuche en la comuna de La Pintana}

La comuna de La Pintana se ubica al sur del Gran Santiago, donde colinda, al norte, con los municipios de San Ramón y La Granja, por el este con La Florida y parte de Puente Alto, por el sur con San Bernardo y Puente Alto, y por el oeste con la comuna de El Bosque (Figura $N^{\circ} 2$ 2). La Pintana nació administrativamente el año 1981 de una escisión de la comuna de La Granja ${ }^{17}$, conformándose luego como municipio el año 1984. Su urbanización se originó no obstante en septiembre del año 1961, a partir de la conformación de la población San Rafael en un terreno de 57 hectáreas de la Chacra Santa Rosa, donde unas 300 familias fueron reasentadas por el Estado, a través de la Corporación de la Vivienda (CORVI), desde la toma de Santa Adriana (Garcés, 2002).

Posteriormente, La Pintana recibiría numerosas familias provenientes de la erradicación de campamentos desde distintos secto-

\footnotetext{
17 El Decreto con Fuerza de Ley $N^{\circ}$ 1-3260 del Ministerio del Interior, promulgado el 9 de marzo de 1981, reorganizó la estructura interna de las provincias que componen la Región Metropolitana, creando a este respecto varias comunas nuevas, en particular en la provincia de Santiago.
} 
res de la capital ${ }^{18}$. Como lo recalca Traverso (2006: 11), "en el período 1979-87 Ilegaron aproximadamente $31 \mathrm{mil}$ personas $(5.969$ familias) que fueron instaladas en ocho poblaciones de erradicación dentro del sector 'El Castillo'". La mayoría de quienes llegaron a La Pintana correspondía a pobladores "sin casa" que, en busca de un lugar donde vivir, habían participado en tomas de terreno, procedían de las Ilamadas poblaciones "callampas" o vivían de allegados en casa de algún pariente, siendo finalmente reasentados a través de diversos programas habitacionales. No es casual que muchos mapuches hayan participado de este proceso, pues su inserción a la vida urbana se hizo en condiciones adversas y de mucha vulnerabilidad ${ }^{19}$.

Desde sus inicios, La Pintana se conoció consecuentemente como una comuna de fuerte presencia indígena. Como lo afirma Carmona (2014: 110):

18 Ver el Plan de Desarrollo Comuna (PLADECO) de La Pintana, disponible en línea: http://www. pintana.cl/transparencia/images/OtrasInfoMunicipal/ PLADECO2012-2016.pdf

${ }^{19} \mathrm{El}$ proceso reciente de formación de "comités de vivienda indígenas" indica que los programas de vivienda social implementados en las décadas pasadas no permitieron solucionar definitivamente el problema. Hoy, son los hijos de quienes fueron asentados a través de estos programas que demandan nuevas soluciones habitacionales. Los "comités de vivienda indígenas" surgieron en este contexto, en el seno de las A.I., como una estrategia que permite movilizar la identidad indígena en pos del acceso a la vivienda social. En respuesta a este proceso, la CONADI y el Ministerio de Vivienda (MINVU) suscribieron en 2007 un convenio de una vigencia de tres años que permitió elaborar un programa de vivienda dirigido a la población indígena residente en áreas urbanas. En el Gran Santiago, se ejecutaron en este marco un total de cinco proyectos habitacionales indígenas (comunicación personal del MINVU a los autores). Por otra parte, notamos que el patrón de inserción de los nuevos migrantes al espacio urbano no parece haber sufrido cambios sustanciales. Aravena (2002: 370) relata, por ejemplo, que, "[...] en Estación Central, comuna eminentemente urbana donde no existen en forma declarada campamentos, hay un parque, el último tramo del Ilamado Parque de las Américas, donde año a año aparecen como "callampas" decenas de casas de material ligero (cartón y madera), de individuos y parejas mapuches que llegan a la gran ciudad por su puerta de entrada ferroviaria". "[la] población mapuche no ha pasado desapercibida para el resto de los vecinos, tampoco para las autoridades municipales y funcionarios que viven actualmente en la comuna, quienes relatan que desde la década de 1980 su presencia en las calles y actividades comunales resulta evidente".

El Censo de Población y Vivienda del año 2002 arrojó, en esta comuna, un total de 11.647 mapuches, equivalentes al 6,12\% de la población total (INE, 2005). En base a estos datos, La Pintana constituiría uno de los municipios con mayor densidad de población mapuche del Gran Santiago (Figura No 2$)^{20}$.

Proponemos, en esta sección, abordar esta realidad desde una perspectiva geográfica, basándonos para ello en un trabajo de campo de cinco meses realizado entre los años 2013 y 2014, en el que se hicieron entrevistas abiertas y/o semiestructuradas a 19 personas; entre ellas funcionarios de la OAI, presidentes y socios activos de siete asociaciones mapuches de La Pintana (Inchiñ Mapu, Tain Adkimn, Kiñe Pu Liwen, Relmu Pichikeche, Ruka Ñanco, Kuifi Lleguen y Rayen Folle) y una de la comuna vecina de La Florida (Kallfullikan, por su alianza con la organización Ruka Ñanco). La elaboración de estas entrevistas apuntó a dilucidar las modalidades de formación y reproducción de espacios colectivos mapuches que, como proponemos en el último apartado, echan las bases de una geografía mapuche urbana. Así también, cabe mencionar que se acompañó a los entrevistados a diversas celebraciones, actividades y talleres culturales, tales como nguillatunes ${ }^{21}$, talleres de telar, juegos de pa-

20 De hecho, solo la comuna de Cerro Navia cuenta con una proporción de población mapuche más elevada en la Región Metropolitana, correspondiendo al 6,48\% de la población comunal (INE, 2005).

21 El nguillatún es una rogativa que convoca a todos los miembros de una misma comunidad y consiste en un acto de petición o ruego a través del cual se pide por las condiciones climáticas y los desastres naturales, por una buena siembra o cosecha y por el bienestar de toda la comunidad en general. Es la ceremonia religiosa de mayor transcendencia dentro el complejo ritual mapuche; puede realizarse año por medio o una y hasta dos veces al año según los sectores y las circunstancias. Su duración varía también notablemente, entre uno y tres días, dependiendo de las localidades. 
lín 22 , ferias costumbristas, entre otros eventos claves de la esfera asociativa mapuche de la comuna. Esta modalidad de observación participante, junto con un trabajo de revisión bibliográfica, permitió complementar los testimonios obtenidos a través de las entrevistas formales.

\section{Proceso asociativo y organización socio- política}

Como fuera señalado más arriba, se advierte cierta tendencia de la población mapuche urbana a concentrarse en determinados barrios y villas. En La Pintana, específicamente, es en las poblaciones Villa España, San Rafael, Eleuterio Ramírez, Santiago de la Nueva Extremadura, y el sector El Castillo donde se observan las concentraciones más significativas de esta población. Junto con conformar espacios claves de sociabilidad para los mapuches de la comuna, estos sectores constituyen una base territorial sobre la cual se articula, en la actualidad, un importante movimiento asociativo mapuche cuyos orígenes es, como en muchas otras comunas de la región, anterior a la promulgación de la legislación indigenista postdictatorial. Notamos, al respecto, que el primer hito del proceso asociativo y de organización sociopolítica mapuche en La Pintana fue la conformación, a principio del año 1990, de la organización Rayen Mapu en el sector El Castillo. Son varias las organizaciones que, al igual que Rayen Mapu, ya se habían conformado -por ejemplo como organizaciones comunitariaso simplemente tenían una existencia "de hecho". En la mayoría de los casos, después del año 1993, estas agrupaciones solicitaron su personería jurídica, conformándose entonces en Asociaciones Indígenas (A.I). De acuerdo a las entrevistas realizadas, muchas de estas organizaciones surgieron a raíz de una iniciativa familiar, generalmente con el propósito de rescatar la identidad mapuche en la ciudad:

\footnotetext{
22 El palín es un deporte tradicional del pueblo mapuche muy similar al hockey sobre césped. Consiste en el enfrentamiento de dos grupos, entendiéndose dicho enfrentamiento como una especie de "guerra ritual" en la que se establece una conexión con los ancestros y se determina una jerarquía entre los participantes.
}

\begin{abstract}
"Nuestra organización se Ilama Inchiñ Mapu y es una de las primeras asociaciones que se funda aquí en nuestra comuna de La Pintana. Nosotros nos conformamos como asociación de hecho en el año 1993 y legal en el año 1995 [...]. Esta asociación se crea por una necesidad de la familia y opta por reunir a personas que son parientes nuestros, para poder trabajar en la mantención cultural y por la necesidad que existe como mapuche de estar reunidos, de mantener la cultura, mantener nuestras tradiciones" 23 .
\end{abstract}

La creación de la OAI de La Pintana, en noviembre de 1996, fue decisiva en este proceso, al poner de manifiesto entre sus lineamientos estratégicos la relevancia de la participación de los pueblos originarios en las decisiones del municipio, y la necesidad de rescatar y recrear su cultura en el contexto urbano. La OAI, que desde sus inicios depende institucionalmente de la Dirección de Desarrollo Comunitario (DIDECO), se creó por la acción conjunta de dirigentes indígenas y autoridades locales, y es atendida hoy día por tres funcionarios. Su presupuesto $-27 \mathrm{mi}$ llones de pesos, destinados en gran medida a solventar los honorarios de los funcionariosproviene de la municipalidad, y es aprobado anualmente por el concejo municipal (Carmona, 2014).

Desde la creación de la OAI hasta la fecha, su labor se ha materializado en un incremento de la asociatividad indígena en La Pintana, donde las 13 A.l. activas al día de hoy reúnen el 3,15\% de la población mapuche de la comuna (Cuadro $N^{\circ} 2$ ). En terreno, la OAI trabaja directamente con 10 de estas asociaciones que apoya a lo largo del año, en la realización de actividades como la celebración del año nuevo mapuche, el Día Internacional de la Mujer Indígena, torneos de palín, talleres de cultura y derechos indígenas, postulación y renovación de la Beca Indígena de la Junta Nacional de Auxilio Escolar y Becas (JUNAEB), gestión de proyectos externos, reuniones de coordinación y promoción de la medicina mapuche en consultorios, entre

\footnotetext{
23 Entrevista realizada a J.H., el 2 de mayo de 2014, en La Pintana.
} 
Cuadro $\mathrm{N}^{\circ} 2$

Asociaciones Indígenas mapuches creadas en La Pintana

\begin{tabular}{|l|c|c|r|}
\hline Organización & Fundación & Estado & \multicolumn{1}{|c|}{ Socios } \\
\hline Inchiñ Mapu & 1995 & Activa & 40 \\
Taiñ Adkimn & 1995 & Activa & 30 \\
Kuyfi Lleguen & 1999 & Activa & 27 \\
Ko Kiyen & 1999 & Activa & 18 \\
Kiñe Liwen & 1999 & Inactiva & - \\
Trhalkan Mawidha & 2000 & Activa & 32 \\
Relmu Pichikeche & 2002 & Activa & 17 \\
We Rayen Mapu & 2002 & Activa & 30 \\
Fottum Mapu & 2002 & Activa & 30 \\
Foliko & 2004 & Activa & 10 \\
Rayen Folle & 2008 & Activa & 31 \\
Ruka Ñanco & 2008 & Activa & 22 \\
Rayen Mapu & 2009 & Activa & 50 \\
Kiñe Pu Liwen & 2010 & Activa & 30 \\
\cline { 2 - 4 } & & Total & 367 \\
\hline
\end{tabular}

Fuente: CONADI y Oficina de Asuntos Indígenas de La Pintana.

otras actividades. Por otra parte, es importante destacar también el compromiso y la participación activa de algunas A.I. en movilizaciones de carácter más político, relativas a la lucha por los derechos indígenas a nivel nacional.

Si bien el movimiento asociativo mapuche se logró posicionar y visibilizar de este modo como un actor importante de la vida social y comunitaria en la comuna, careció durante muchos años de un espacio propio que le fuera formalmente reconocido y que por lo mismo empezó a reclamar. El año 2000 marcó un punto de inflexión importante en este sentido, pues una serie de iniciativas, tales como la postulación a fondos de cultura (FONDART), fondos CONADI, fondos extranjeros, y algunos proyectos de universidades tradicionales ${ }^{24}$, permitieron que las organizaciones mapuches pudiesen establecerse en

\footnotetext{
24 Precisamente, la Pontificia Universidad Católica de Chile y la Universidad de Chile.
}

espacios cedidos a comodato por la municipalidad, y en el caso de la A.I. Taiñ Adkimn por la Universidad de Chile (Thiers, 2012). Antes de esta fecha, las asociaciones solo contaban con sedes vecinales prestadas por el municipio o, en algunos casos, se reunían en casas y terrenos particulares de los mismos socios. No obstante, por sus características, estos espacios no se adecuaban a las necesidades de las organizaciones que empezaron a buscar otras alternativas.

\section{La formación de espacios colectivos mapuches en La Pintana}

Producto de las movilizaciones y negociaciones de las asociaciones con distintas instituciones, públicas y privadas, el año 2000 se levantaron en la comuna dos rukas -vivienda mapuche tradicional-, en el consultorio Santiago de la Nueva Extremadura y el jardín infantil Kipai Antu. Gestionadas por las organizaciones Ruka Ñanco y Relmu Pichikeche, respectivamente, estas rukas fueron construidas con la finalidad de recuperar, difundir y practicar la cultura mapuche en La Pintana. 
Cuadro $\mathrm{N}^{\circ} 3$

Espacios colectivos mapuches formados en la comuna de La Pintana

\begin{tabular}{|c|c|c|c|}
\hline Nombre del espacio & $\begin{array}{l}\text { Año de } \\
\text { creación }\end{array}$ & $\begin{array}{l}\text { Organizaciones } \\
\text { encargadas }\end{array}$ & Instituciones involucradas \\
\hline $\begin{array}{l}\text { Ruka Consultorio } \\
\text { Santiago de la Nueva } \\
\text { Extremadura }\end{array}$ & 2002 & Ruka Ñanco & $\begin{array}{l}\text { OAI de La Pintana } \\
\text { Pontificia Universidad Católica de Chile } \\
\text { Consultorio Santiago de la Nueva Extre- } \\
\text { madura } \\
\text { Embajada de Canadá }\end{array}$ \\
\hline Ruka Kipai Antu & 2000 & Relmu Pichikeche & $\begin{array}{l}\text { OAI de La Pintana } \\
\text { Jardín Infantil Intercultural Kipai Antu }\end{array}$ \\
\hline Ruka Kiñe Pu Liwen & 2002 & Kiñe Pu Liwen & $\begin{array}{l}\text { Fondo Nacional de Desarrollo Cultural y } \\
\text { las Artes (FONDART) } \\
\text { Fondo Social del Ministerio del Interior }\end{array}$ \\
\hline $\begin{array}{l}\text { Centro Ceremonial } \\
\text { Mapu Lawen }\end{array}$ & 2003 & $\begin{array}{l}\text { Foliko } \\
\text { Fotum Mapu } \\
\text { Inchiñ Mapu } \\
\text { Ko Killen } \\
\text { Kuifi Lleguen } \\
\text { Rayen Folle } \\
\text { Rayen Mapu } \\
\text { Relmü Pichikeche } \\
\text { Tralkan Mawida } \\
\end{array}$ & $\begin{array}{l}\text { Corporación Nacional de Desarrollo Indí- } \\
\text { gena (CONADI) } \\
\text { OAI de La Pintana } \\
\text { Servicio Nacional de Menores (SENAME) }\end{array}$ \\
\hline Ruka Taiñ Adkimn & 2005 & Taiñ Adkimn & Universidad de Chile \\
\hline
\end{tabular}

Fuente: Elaboración propia.

Posteriormente, las organizaciones Kiñe Pu Liwen e Inchiñ Mapu levantaron también sus propias rukas, en 2002 y 2004 respectivamente. La construcción de una segunda ruka en el recinto de la A.I. Inchiñ Mapu, en base a un trabajo con la OAl y otras A.I. de la comuna, permitió la formación, en 2010, de lo que se conoce hoy como el Centro Ceremonial Mapu Lawen ${ }^{25}$. Finalmente, en el 2005, la A.I. Taiñ Adkimn construyó una quinta ruka

\footnotetext{
${ }^{25}$ El Centro Ceremonial Mapu Lawen tiene una extensión de $5.000 \mathrm{~m}^{2}$. Se han conformado también otros recintos de similares características en otras comunas del Gran Santiago, tales como el Parque Ceremonial Newen Meli Witran Mapu de Cerro Navia y el Parque de Pueblos Originarios Mahuidache de El Bosque (Thiers, 2012).
}

en el campus Antu Mapu de la Universidad de Chile (Cuadro $N^{\circ} 3$ y Figura $N^{\circ} 5$ ). Es importante destacar la participación e influencia en este proceso de numerosos actores no mapuches, instituciones públicas y privadas, y en particular de la OAI, que contempla, dentro de sus lineamientos, "buscar espacios para desarrollar el arte, las ceremonias, las ritualidades, el deporte, como una forma de recreación propia de la manera en como la entiendan los pueblos indígenas" 26 .

En cuanto a sus características morfológicas, estas rukas retoman en su mayoría el

\footnotetext{
${ }^{26}$ Entrevista realizada a J.P., el 9 de diciembre de 2014, en La Pintana.
} 
Figura $\mathrm{N}^{\circ} 3$

Rukas Taiñ Adkimn (izquierda) y Santiago de la Nueva Extremadura (derecha)

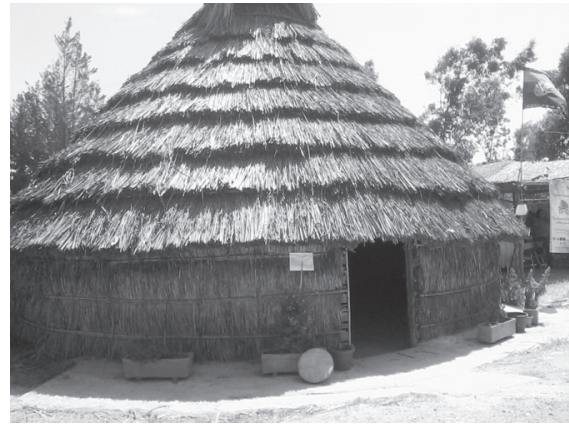

Fuente: Archivo personal de los autores, 2014

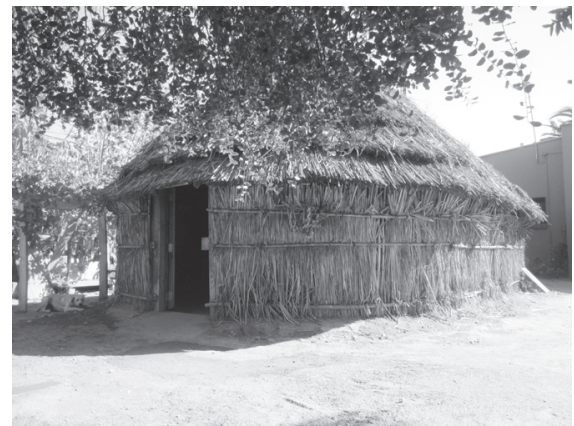

mismo diseño que aquellas construidas en las comunidades del sur' ${ }^{27}$ su estructura, hecha de coligüe, eucalipto, pino y totora, es de forma ovalada, con la puerta principal orientada hacia el oriente, y su superficie varía entre 1.000 y $5.000 \mathrm{~m}^{2}$ (Figura $\mathrm{N}^{\circ}$ 3). En su interior, todas cuentan con un fogón central, ornamentaciones como telares, textiles, cuelgas de vegetales, cerámicas, instrumentos musicales, etc. Algunas lucen también elementos no tradicionales como piso de radier, cerámica, luz eléctrica, agua potable, televisores, camillas, equipos musicales y otros materiales de utilidad para las distintas actividades programadas. En las inmediaciones de la

\footnotetext{
${ }^{27}$ Las rukas, que habían desparecido de los campos del sur tras la implementación de subsidios para la vivienda rural en el transcurso de los años 70 , volvieron a aparecer en las últimas dos décadas, en el surco del desarrollo turístico. Desde mediados de los años 90, el turismo ha entrado efectivamente con mucha fuerza en las comunidades mapuches, y las rukas se han impuesto, en este contexto, como un elemento diferenciador, sirviendo de base a un tipo de turismo muchas veces calificado de "étnico". Existe así hoy en día un gran número de rukas que funcionan tanto como museos, centros de eventos, o para servicios de hostería. En algunos sectores, incluso, algunas rukas se han convertido en el punto de partida de circuitos que ofrecen al turista una inmersión "total" en el universo cultural mapuche. La ruka se ha dado a ver de esta forma como un espacio idóneo de reproducción de la cultura mapuche. Ello explica probablemente que, en la ciudad, quienes participan del movimiento asociativo mapuche tiendan a percibir e idealizar a la ruka como un espacio identitario primordial.
}

ruka, suele haber una abundante vegetación compuesta, entre otros, de foyes o canelos (Drimys winteri), el árbol sagrado del pueblo mapuche, huertos con hierbas medicinales y otros elementos de importancia cultural, como son el rewe ${ }^{28}$ y los Chemamul/29. Desde esta perspectiva, las rukas no parecieran estar insertas en un contexto urbano, intentando más bien reproducir el entorno de las comunidades de origen en el sur del país.

De hecho, los espacios de las rukas suelen también ser utilizados para la celebración de ceremonias y rituales tradicionales de gran importancia que permiten reconectar los urbanos con el mundo comunitario de origen. El wiñoy xipantu o we tripantu, el año nuevo mapuche, por ejemplo, se celebra todos los años en cada una de las rukas de la comuna, usualmente entre los días 21 y 24 de junio, al momento del solsticio de invierno. Es común, en este tipo de instancias, la asistencia de autoridades locales y funcionarios municipales, cuya presencia "propicia una discusión en torno a la situación actual del pueblo

${ }^{28}$ El rewe es un altar sagrado compuesto por peldaños tallados en un tronco de madera y ubicado al centro del nguillatué, que es el campo donde se realizan las ofrendas y los sacrificios. Encarna lo divino en la tierra, permitiendo al / a la machi acceder al mundo sobrenatural y conectarse con los espíritus.

${ }^{29}$ Los Chemamull son estatuas de madera que representan las dos parejas de ancianos y jóvenes mapuches. El término se descompone de la siguiente manera: Che $=$ persona y Mamull $=$ madera. 

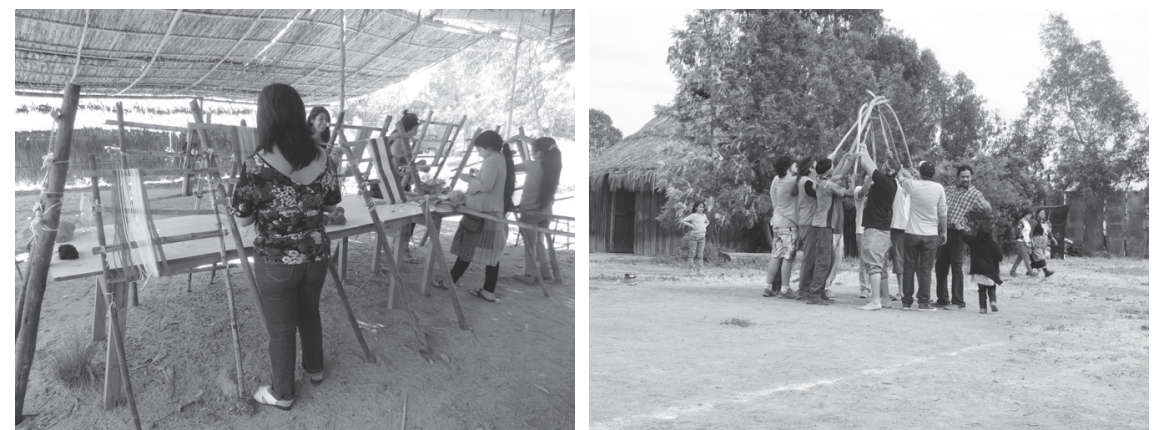

Fuente: Archivo personal de los autores, 2014.

mapuche, generando un momento clave de negociación" (Carmona, 2014: 128). Otra ceremonia de gran trascendencia es el nguiIlatun que, a diferencia del we tripantu, solo se celebra en algunas rukas -Kiñe Pu Liwen, Taiñ Adkimn y el Centro Ceremonial Mapu Lawen- y en fechas variables según los años. El nguillatun del Centro Ceremonial Mapu Lawen es el que reúne la mayor cantidad de organizaciones y, por consiguiente, el mayor número de participantes también, alcanzando más de 2.500 personas provenientes no solo de La Pintana, sino también de otras comunas como Cerro Navia, Maipú, Peñalolén, entre otras.

Más allá de la celebración de estas ceremonias, las rukas son también espacios de reunión donde, a lo largo del año, se realizan diversas actividades, de carácter educativo, deportivo, etc., abiertas a toda la comunidad, mapuche y no mapuche ${ }^{30}$. Un ejemplo de ello son los talleres de telar o witral que se organizan en algunas rukas y que, según

\footnotetext{
30 Las actividades que se realizan en las rukas son en general abiertas para todo tipo de público, pues de acuerdo a los entrevistados es fundamental que la comunidad conozca y se acerque más a la cultura mapuche. Desde esta perspectiva, la difusión de estas actividades se realiza por diversos medios de comunicación, entre ellos la OAl, afiches en las calles, y a través de redes sociales, como por ejemplo el Facebook de las organizaciones o la página web Santiago Mapuche (www.santiagomapuche.com), donde se convoca a participar de diversas actividades durante todo el año.
}

las observaciones realizadas en terreno, se transforman en importantes espacios de sociabilización en que las mujeres se reúnen para contar y compartir sus experiencias de vida y conocimiento en torno a esta práctica cultural. Otro caso interesante son los juegos de palín que se realizan en fechas puntuales según acuerdo de las organizaciones y que, a diferencia de los talleres de telar, son espacios eminentemente masculinos (Figura $\mathrm{N}^{\circ} 4$ ).

Cabe precisar, además, que si bien estas rukas surgieron inicialmente de la necesidad expresada por las asociaciones de contar con un espacio propio, muchas de estas iniciativas se concretaron a través de la participación en concursos públicos y la asignación de recursos provenientes de distintos fondos, tanto nacionales como internacionales. La estrecha relación de múltiples actores institucionales con la creación de estas rukas ha gatillado que estos espacios se visualicen, en el transcurso del tiempo, como un foco idóneo de inversión de políticas públicas de enfoque multicultural. Así, por ejemplo, contar con una ruka como espacio donde implementar un programa ligado al desarrollo de la salud intercultural o educación intercultural bilingüe puede constituir, frente a los organismos financieros, una ventaja decisiva.

Pero más que un lugar en que se plasma, simboliza y "negocia" en cierta forma la identidad mapuche en la ciudad, la ruka se presenta ante todo como un espacio de sociabilización donde los individuos comparten sus vivencias y expresan su etnicidad. Como 
lo afirmó una entrevistada, "[la ruka] es un lugar sagrado, esto es lo que nosotros tenemos en ese pequeño espacio. Para eso está ese lugar, nosotros los mapuches tenemos reuniones, contamos nuestras penas, nuestros problemas, nuestros proyectos durante el año, lo que vamos a hacer, lo que no vamos a hacer" ${ }^{\prime \prime 1}$. A diferencia de otros espacios también utilizados en determinadas ocasiones por las organizaciones, como son algunas sedes vecinales o consultorios de la comuna, las rukas permiten a la comunidad mapuche urbana inscribir su identidad y resignificar su presencia en el medio urbano, echando así las bases de una geografía mapuche urbana.

\section{Rukatun o las fundaciones de una geografía mapuche urbana}

Nos interesa dar cuenta, en esta última parte, de cómo los espacios colectivos construidos en torno a las rukas -el hacer ruka o rukatun- contribuyen a territorializar la comunidad mapuche de La Pintana. El primer elemento que merece ser destacado, en este sentido, es la ausencia de correlación geográfica entre los recintos que albergan las distintas rukas y las poblaciones o villas con mayores concentraciones de población mapuche. Las rukas y sedes comunitarias mapuches se ubican de hecho preferentemente en el sector central y noroeste de la comuna, donde se halla también la mayor cantidad de servicios públicos: Municipalidad, consultorios, etc. (Figura $\mathrm{N}^{\circ}$ 5).

Vale recalcar que estos sectores son también aquellos donde la disponibilidad de espacio permitió el establecimiento de las rukas en terrenos amplios y planos. Las entrevistas realizadas dan cuenta al respecto de la necesidad de un entorno que se asimile al de las comunidades de origen, es decir abierto, natural, sin cemento, silencioso y tranquilo. Como lo aseveró uno de los entrevistados, la ruka "es un círculo un poco más grande donde tú estás hablando con tu tierra, pisas tierra, no cemento [...], y hay foye, hay maqui, todo lo que el mapuche tiene en su

\footnotetext{
31 Entrevista realizada a R.P., el 13 de enero de 2014, en La Pintana.
}

campo" $^{\prime 32}$. Estas características, que remiten a un ambiente más prístino, permiten individualizar y a la vez diferenciar el espacio mapuche del entorno urbano. El etnónimo mapuche, que significa "gente de la tierra"33, recobra de esta forma todo su sentido.

Es también importante señalar el rol fundamental que cabe a la cosmovisión mapuche en el proceso de construcción de estos espacios colectivos. Pues, en las entrevistas, se mencionó que antes de construir y comenzar a asear el espacio, se debía realizar una limpieza espiritual a través de oraciones dirigidas a los ngen mapu, o "dueños de la tierra", a quienes se debe solicitar permiso para ocupar el lugar:

"Primero se limpió el lugar, y se limpió no con la escoba, se limpió con oración, porque nosotros creemos en los ngen mapu que son los dueños. Todos los espacios tienen su dueño, el bosque tiene un ngen, el río tiene un ngen, el mar tiene un ngen, todos estos tienen ngen, dueños, porque ngen significa dueño de un lugar específico" ${ }^{\prime 34}$.

Junto con reafirmar una identidad diferenciada, el requerir permiso a los ngen mapu permite apropiarse simbólica y materialmente del espacio, informarlo, dotarlo de significado y convertirlo finalmente en territorio. La implementación de una ruka responde por lo tanto a una voluntad colectiva cuya materialización, en consecuencia, también involucra a todos los miembros del grupo, quienes observan determinados protocolos y códigos socioculturales al momento de repartirse el trabajo:

"Pedro es rukafe, él construyó [la ruka] con otros hermanos mapuches varones, porque son los hombres quienes deben construir la ruka. Nosotras fuimos parte de la ceremonia de autorización del espacio acá con la machi; mientras los hombres construían la ruka, estábamos

\footnotetext{
32 Entrevista realizada a R.P., el 13 de enero de 2014, en La Pintana.

33 La palabra mapuche se descompone de la siguiente manera: $\mathrm{Mapu}=$ tierra y $\mathrm{Che}=$ gente

${ }^{34}$ Entrevista realizada a J.H., el 2 de mayo de 2014, en La Pintana.
} 


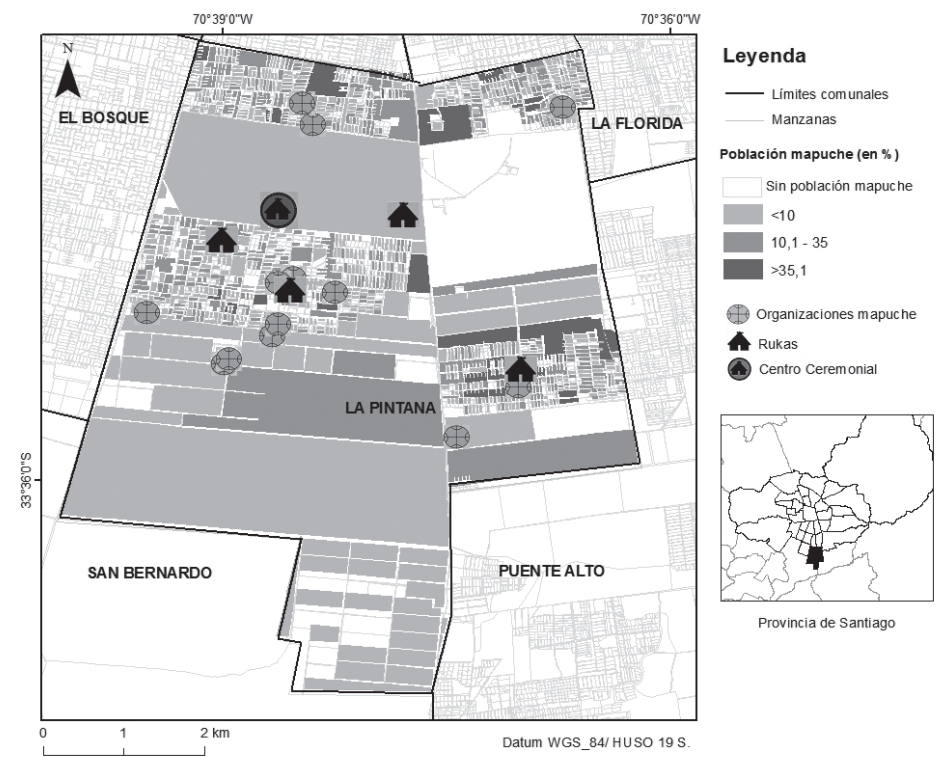

Fuente: Elaboración propia.

agarrando totoras, preparando comida, enseñándoles a los hijos e hijas como se hacía la ruka, pero fue todo familiar, todo como comunidad mapuche, como tiene que ser" 35 .

El proceso de construcción de la ruka viene entonces a dar cuerpo y sentido a la formación e idea misma de una comunidad indígena urbana, reflejando asimismo las complejas dinámicas de territorialización mapuche en el medio urbano. Al imponerse como un elemento de mucha trascendencia en la (re)producción de la identidad mapuche en la comuna de La Pintana, la ruka marca un "dentro" y un "fuera", afirmándose así como un espacio diferenciado, propiamente mapuche, visible en el mosaico urbano. Una de las entrevistadas afirma incluso que

"la ruka es la embajada de la nación mapuche, salgo de la ruka y piso Chile, entro a la ruka y piso nación mapuche [...]. Mi

\footnotetext{
${ }^{35}$ Entrevista realizada a M.H., el 11 de enero de 2014 , en La Pintana.
}

sangre latía fuerte cuando entré a la ruka, me cayeron unas lágrimas, era lo mío, como que me reconocí"36.

La ruka remite indudablemente a un entorno diferenciado que, para los "mapuches del cemento", evoca la vida en el territorio de origen y los reconecta de este modo con sus raíces. En este sentido, la ruka no se constituye solamente a través de su materialidad, sino que se conforma también en un espacio simbólico en el que los mapuches de ciudad se (re)encuentran con su etnicidad, (re)definen su identidad y (re)negocian su posición en el mosaico urbano.

\section{Conclusión}

Las rukas se han afirmado como elementos claves en el proceso de territorialización de la población mapuche en La Pintana. Junto con marcar el paisaje urbano con su arquitectura singular, las rukas permiten dar

\footnotetext{
36 Entrevista realizada a R.M., el 7 de mayo de 2014, en La Pintana.
} 
visibilidad a los mapuches de la comuna, pero también resignificar un espacio inicialmente ajeno, dotándolo de identidad. Como lo hemos analizado, el propio proceso de construcción de las rukas, al pedir permiso a los espíritus protectores del lugar, constituye un acto altamente simbólico que marca una forma de apropiación cultural del espacio y reafirma la condición étnica de los actores involucrados y su inscripción en un universo que traspasa los límites de la comuna. A su vez, no debe perderse de vista que la edificación de estas rukas resulta también de negociaciones con diversas instituciones, tanto públicas como privadas, que juegan un papel fundamental en la materialización y orientación de los procesos analizados, y por consiguiente en la conformación de una geografía indígena urbana. En definitiva, la experiencia mapuche en la comuna de La Pintana demuestra que, más que un lugar de asimilación, la ciudad puede ser considerada como un espacio de reafirmación identitaria y, por consiguiente, de recomposiciones territoriales. Dicho de otro modo, los centros urbanos y sus periferias participan plenamente de las dinámicas territoriales que animan el mundo mapuche contemporáneo.

Así también, al reivindicar su sitio en la ciudad, las organizaciones indígenas y sus representantes desafían los fundamentos y presuposiciones de una modernidad espacial que pretende inscribir lo urbano y lo indígena en una relación dicotómica. En este sentido, la experiencia analizada en este artículo problematiza las representaciones hegemónicas de lo indígena en tanto identidad anclada en un espacio y una tradición ahistóricos, constitutivos de una forma de exclusión socioespacial. La realidad mapuche urbana no solo evidencia una manera singular de posicionarse en, y con respecto a la ciudad, sino que también devela las múltiples formas de dar sentido a los lugares, inscribiendo de este modo la ciudad en la geografía de un territorio cuya concepción, muchas veces restringida y relegada al universo de las reducciones, se ve consecuentemente ampliada. A imagen y semejanza de las reservas indígenas de Canadá, las reducciones mapuches creadas al sur del río Biobío constituyeron efectivamente, por mucho tiempo, una suerte de "medio natural indio" (Comat, 2012), dibujando así los contornos de una "mapuchidad" permitida, definida por la coerción del poder colonial.

Si bien, como lo afirma Watson (2010), las urbanidades indígenas develan el carácter "problemático" de dichas representaciones, cuestionan al mismo tiempo los fundamentos de una modernidad espacial cuya imposición no logra ocultar la complejidad y la fluidez de las reestructuraciones territoriales contemporáneas. Refiriéndose a la experiencia de los ainus en Japón, Watson (2010) propone hablar al respecto de una "indigeneidad diaspórica" que, al conectar una multitud de lugares geográficamente distanciados entre sí, trasciende la clásica dicotomía urbano / rural. En este contexto, los territorios y comunidades de origen siguen constituyendo, para los migrantes y sus descendientes, espacios de referencia cuya movilización otorga sentido a la acción colectiva indígena en la ciudad. Es el caso en Japón (Watson, 2010), pero también en Canadá donde Wilson y Peters (2005) observan que la celebración de ceremonias y ritos tradicionales permite a los llamados "urbanos" resignificar su pertenencia a una comunidad y a un territorio de contornos más topológicos que topográficos. Estos procesos, como lo hemos visto en este trabajo, se dan también en Chile con los mapuches.

La urbanidad se plantea así como un verdadero desafío en términos teóricos para el desarrollo de las geografías indígenas, particularmente en América Latina donde existe una incipiente producción académica volcada al estudio de los territorios indígenas. Pero constituye también un desafío en términos metodológicos, considerando que la toma en cuenta de la urbanidad, y de la ciudad como un espacio central en las geografías indígenas contemporáneas, contribuiría a descolonizar las representaciones del territorio basadas en el paradigma moderno. Pues, más que una superficie cerrada cuyos límites estarían clara y definitivamente establecidos, el territorio es un objeto complejo que, siguiendo las movilidades y motivaciones de quienes le dan cuerpo, se encuentra en constante reestructuración. El espacio urbano constituye, en este sentido, un verdadero laboratorio geográfico cuya consideración es imprescindible al momento de abordar las geografías indígenas. Una geografía consecuente de los territorios indígenas no puede eludir la realidad urbana, 
de tal manera que no aparece incongruente ni inconsistente proponer, siguiendo a Watson (2010), "urbanizar los estudios indígenas". La invitación es entonces a incentivar el interés por las geografías indígenas urbanas, considerando que la ciudad no solo es practicada y apropiada por las comunidades de migrantes, sino que también es integrada, incorporada a la estructura territorial indígena en la cual tiende a ocupar un lugar cada vez más importante.

\section{Referencias bibliográficas}

ALISTE, E. Trayectoria territorial de la conurbación Concepción-Talcahuano: industria, asentamientos humanos y expresión espacial del desarrollo, 1950-2000. En: PÉREZ, L. y HIDALGO, R. (editores). Concepción metropolitano. Evolución y desafíos. Concepción: Editorial Universidad de Concepción, 2010, p. 123-149.

ALMONACID, F. La división de las comunidades indígenas del sur de Chile, 19251958: un proyecto inconcluso. Revista de Indias, 2008, Vol. 68, No243, p. 115-150.

ANDERSON, K. \& JACOBS, J. From Urban Aborigines to Aboriginality and the City. Australian Geographical Studies, 1997, Vol. 35, $\mathrm{N}^{\circ} 1$, p. 1-22.

ARAVENA, A. Identidad indígena en Chile en contexto de migración, urbanización y globalización. Les Cahiers ALHIM, 2014, Nº 27. Disponible en Internet: http://alhim.revues.org/4942

ARAVENA, A. Mapuches en Santiago. Memorias de inmigrantes y residentes. Relatos para una antropología implicada sobre indígenas urbanos. Concepción: Ediciones Escaparate, 2007.

ARAVENA, A. Los Mapuche-Warriache: migración e identidad mapuche urbana en el siglo XX. En: BOCCARA, G. Colonización, resistencia y mestizaje en Las Américas (siglos $X V I-X X)$. Quito / Lima: Ediciones Abya Yala / Instituto Francés de Estudios Andinos (IFEA), 2002, p. 359-385.
BELLO, A. Migración, identidad y comunidad mapuche en Chile: entre utopismos y realidades. Asuntos Indígenas, 2002, No 3-4, p. 40-47.

BENGOA, J. Historia del pueblo mapuche. Siglo XIX y XX. Santiago de Chile: LOM Ediciones, 1985 [1999].

CARMONA, R. Mapuche urbanos y gobierno local. Etnografía de la Oficina de Asuntos Indígenas, comuna de La Pintana. Santiago de Chile: Tesis para optar al grado de Magíster en Antropología, Universidad Academia de Humanismo Cristiano, 2014.

COMAT, I. Sortir de l'invisibilité : comprendre la place de la ville dans les territoires autochtones contemporains sous l'angle juridique. Géographie et Cultures, 2012, № 81, p. 57-74.

DÍAZ, A. La Alameda de Monterrey: espacio estratégico de encuentro de los migrantes indígenas de la Huasteca. En: DURIN, S. Entre luces y sombras. Miradas sobre los indígenas en el Area Metropolitana de Monterrey. México: Centro de Investigaciones y Estudios Superiores en Antropología Social (CIESAS) / Comisión Nacional para el Desarrollo de los Pueblos Indígenas (CDI), 2008, p. 139-171.

DYBBROE, S.; DAHL, J. y MÜLLER-WILLE, L. Acta Borealia, 2010, Vol. 27, N²: History Matters: Dynamics of Arctic Urbanization, p. 120-124.

GARCÉS, M. Tomando su sitio. El movimiento de pobladores de Santiago, 1957 1970. Santiago de Chile: LOM Ediciones, 2002.

GISSI, N. Asentamiento e identidad mapuche en Santiago: entre la asimilación (enmascaramiento) y la autosegregación (ciudadanía cultural). En: COLEGIO DE ANTROPÓLOGOS DE CHILE. Actas del Cuarto Congreso Chileno de Antropología. Santiago de Chile, 2001.

GONZÁlEZ, H. Propiedad comunitaria o individual. Las leyes indígenas y el pueblo mapuche. Nütram, 1986, Vol. 2, No 3, p. 7-13. 
HIERNAUX-NICOLAS, D. La inserción urbana de la población indígena en la Ciudad de México. En: BODSON, P., CORDERO, A., CARRASCO, P. y GOULET, J. Vivir en la ciudad. Lo cotidiano de la inserción urbana en México, América Central y el Caribe. San José: FLACSO-Costa Rica, 2005, p. 253-272.

HIERNAUX-NICOLAS, D. Metrópoli y etnicidad. Los indígenas en el valle de Chalco. México: El Colegio Mexiquense, Fondo Nacional para la Cultura y las Artes, H. Ayuntamiento Valle de Chalco Solidaridad, 2000.

HOWARD, H. \& PROULX, C. Aboriginal Peoples in Canadian Cities. Transformations and Continuities. Waterloo: Wilfrid Laurier University Press, 2011.

IMILAN, W. y ÁLVAREZ, V. El pan mapuche. Un acercamiento a la migración mapuche en la ciudad de Santiago. Revista Austral de Ciencias Sociales, 2008, No 14, p. 23-49.

INSTITUTO NACIONAL DE ESTADÍSTICAS (INE). Estadísticas sociales de los pueblos indígenas en Chile-Censo 2002. Santiago de Chile: Ministerio de Planificación, Gobierno de Chile, 2005.

KISHIGAMI, N. \& LEE, M. Etudes/Inuit/ Studies, 2008, Vol. 32, $N^{\circ} 1$ : Les Inuit urbains / Urban Inuit, p. 5-11.

MILlALEO, A. Ser "Nana" en Chile: un imaginario cruzado por género e identidad étnica. Santiago de Chile: Tesis para optar al grado de Magíster en Estudios de Género, Universidad de Chile, 2011.

MILLALEO, A. Multiplicación y multiplicidad de las organizaciones mapuche urbanas en la Región Metropolitana. ilncremento en la participación mapuche o fragmentación organizacional? Santiago de Chile: Universidad ARCIS, Escuela de Sociología, 2006.

MORGAN, G. \& GULSON, K. Environment and Planning A, 2010, Vol. 42, $\mathrm{N}^{\circ} 2$ : Indigenous People and Urbanization, p. 265267.

MUNIZAGA, C. Vida de un araucano. El estudiante mapuche Lorenzo Aillapán en Santiago de Chile, en 1959. Santiago de Chile:
Departamento de Ciencias Antropológicas y Arqueología, Universidad de Chile, 1971.

NEWHOUSE, D. \& PETERS, E. Not Strangers in These Parts. Urban Aboriginal Peoples. Ottawa: Government of Canada Publications, 2003.

PETERS, E. Urban Aboriginal Policy Making in Canadian Municipalities. Montréal: McGill-Queen's University Press, 2012.

PETERS, E. Emerging Themes in Academic Research in Urban Aboriginal Identities in Canada, 1996-2010. Aboriginal Policy Studies, 2011, Vol. 1, No 1, p. 78-105.

PETERS, E. \& ANDERSEN, C. (director). Indigenous in the City. Contemporary Identities and Cultural Innovation. Vancouver: UBC Press, 2013.

RUPAILAF, R. Las organizaciones mapuches y las políticas indigenistas del Estado chileno (1970-2000). Revista de la Academia, 2002, N ${ }^{\circ} 7$, p. 59-103.

SAAVEDRA, A. Los Mapuche en la sociedad chilena actual. Santiago de Chile / Valdivia: LOM Ediciones / Universidad Austral de Chile, 2002.

SEJERSEN, F.; THISTED, K. \& THUESEN, S. The Urban Arctic. Living Communities: New Perspectives on Inuit Urban Life. Copenhague: Eskimology and Arctic Studies Section / International School for Studies of Arctic Societes (IPSSAS), 2008.

SEPÚLVEDA, B. Recompositions territoriales autochtones en milieu urbain. Urbanisation et urbanité mapuche au Chili. Recherches amérindiennes au Québec, 2011, Vol. 41, No2-3, p. 117-128.

STUCHLIK, M. La vida en mediería. Mecanismos de reclutamiento social de los mapuches. Santiago de Chile: Soles Ediciones, Reedición traducida al español, 1976 [1999].

THIERS, J. La población mapuche en Santiago de Chile, 1990-2012. Entre la tradición y la modernidad. Barcelona: Trabajo de seminario para optar al título de Máster Oficial 
Europeo en Planificación Territorial y Gestión Ambiental, Universidad de Barcelona, 2012.

TRAVERSO, G. Historia y configuración socio-espacial del sector El Castillo, comuna La Pintana. Aproximación al ghetto en el estudio de la geografía social. Santiago de Chile: Memoria para optar al Título Profesional de Geógrafa. Universidad de Chile, 2006.

VALDÉS, M. Notas sobre la población mapuche de la Región Metropolitana: un avance de investigación. Pentukun, 1996, № 5, p. 41-66.
WATSON, M. Diasporic Indigeneity: Place and the Articulation of Ainu Identity in Tokyo, Japan. Environment and Planning $A$, 2010, Vol. 42, No 2, p. 268-284.

WILSON, K. \& PETERS, E. 'You can make a place for it'. Remapping Urban First Nations Spaces of Identity. Environment and Planning D, 2005, Vol. 23, Nº3, p. 395-413. 
